\title{
Pensamento computacional na formação de professores: experiências e desafios encontrados no ensino da computação em escolas públicas
}

\author{
Vladimir Silva ${ }^{1}$, Klebson Silva ${ }^{1}$, Rozelma Soares de França ${ }^{2}$ \\ ${ }^{1}$ Departamento de Estatística e Informática (DEINFO) - Universidade Federal Rural de \\ Pernambuco (UFRPE) CEP 52171 - 900 - Recife - PE - Brazil \\ ${ }^{2}$ Departamento de Educação (DEd) - Universidade Federal Rural de Pernambuco \\ (UFRPE) CEP 52171 - 900 - Recife - PE - Brazil \\ \{vladimirgsilva, luis.klsilva, rozelma\} @ufrpe.br
}

\begin{abstract}
The teaching of computing as a science in public schools in Brazil is not yet a reality, although there are initiatives on the subject. Numerous factors contribute to this, such as the lack of public policies for the integration of computing into the school curriculum, investment in educational technologies, and teacher training to use these resources. In this context, the curricular internship discipline of the course of Degree in Computing of Rural Federal University of Pernambuco facilitated the experience of a teacher training project of public schools in computational thinking $(P C)$, seeking to disseminate computing as an interdisciplinary science. As a result of this project, it can be mentioned that before the training the teachers did not have knowledge about the subject PC, however, they increased their perception on the subject, under interdisciplinary looks and expressed the intention to apply the knowledge built in their classrooms.
\end{abstract}

Resumo. O ensino de computação, como ciência, nas escolas públicas do Brasil ainda não é uma realidade, apesar de haver iniciativas sobre o tema. Inúmeros fatores contribuem para isso, como a falta de políticas públicas para a integração da computação no currículo escolar, o investimento em tecnologias educacionais e a da formação docente para uso desses recursos. Neste contexto, a disciplina Estágio Curricular V do curso de Licenciatura em Computação da Universidade Federal Rural de Pernambuco oportunizou a vivência de um projeto de formação de professores de escolas públicas em pensamento computacional (PC), buscando difundir a computação como uma ciência interdisciplinar. Como resultados deste projeto, pode-se mencionar que antes da formação os professores não possuíam conhecimento sobre o tema PC, contudo, ampliaram sua percepção sobre o tema, sob olhares interdisciplinares e manifestaram pretensão de aplicar os conhecimentos construídos em suas salas de aula.

\section{Introdução}

O ensino da computação, como ciência, nas escolas não visa tão somente a empregabilidade do educando, mas sim formar cidadãos capazes de resolver problemas do seu cotidiano. A essa habilidade, Wing (2006) denominou de Pensamento Computacional (PC). O PC utiliza-se de uma variedade de ferramentas mentais para a 
VI Congresso Brasileiro de Informática na Educação (CBIE 2017)

Anais do XXIII Workshop de Informática na Escola (WIE 2017)

resolução de problemas e envolve etapas como: abstração, modelagem e automatização. Segundo Carvalho (2013) a importância do PC tem ganhado reconhecimento em vários países, existindo inúmeras publicações sobre o assunto (BARR \& STEPHENSON, 2011; DENNING, 2009; HU, 2011; WING, 2006, 2008).

Há barreiras e desafios a serem superados para pôr em prática o ensino de tal habilidade computacional nos níveis de ensino fundamental e médio no Brasil. Entre estes desafios, pode-se destacar a infraestrutura inadequada das escolas, em que na grande maioria não disponibilizam de um laboratório de informática adequado para a prática.

Nesse âmbito, Soares Neto et al. (2013) destacam que $40 \%$ das escolas são classificadas como tendo infraestrutura básica e essas escolas têm as seguintes características gerais: dispõe de água, sanitário, energia, esgoto, cozinha, sala de diretoria e equipamentos como TV, DVD, computadores e impressora. Por outro lado, apenas $15,5 \%$ das escolas brasileiras têm características mais sofisticadas que essas, ou seja, as escolas classificadas como tendo infraestrutura escolar adequada e avançada, que possuem laboratórios de informática.

Outro fator é a falta de planejamento para execução de cursos da área de computação e a formação de professores, sendo este fundamental para a boa prática de ensino de PC nas escolas e que é foco deste trabalho.

Diante desse cenário entende-se que há uma necessidade de desenvolver práticas pedagógicas que envolvam atividades lúdicas com o uso da computação. Portanto, um curso foi desenvolvido para professores que atuam na educação básica, o qual teve como objetivo apresentar o conceito do PC e sua aplicabilidade em sala de aula através de atividades lúdicas com o uso de ferramentas educacionais que abordam diferentes conceitos da ciência da computação, como o estudo da lógica de programação.

Nesse contexto, este trabalho apresenta os resultados obtidos com tal formação a qual foi vivenciado na disciplina Estágio Supervisionado V do curso de Licenciatura em Computação da Universidade Federal Rural de Pernambuco (UFRPE) e que contou com a participação de professores multiplicadores do Centro de Tecnologia na Educação (CETEC) da cidade do Recife.

O restante do trabalho está estruturado como segue: na seção 2 PC é definido e trabalhos relacionados ao tema são apresentados; a seção 3 ilustra recursos que podem ser usados no ensino de PC; as seções 4 e 5 descrevem, respectivamente, a experiência vivenciada e os resultados alcançados nesta pesquisa. Por fim, as seções 6 e 7 trazem respectivamente as considerações finais acerca de todo o trabalho e os agradecimentos.

\section{Fundamentação teórica e trabalhos relacionados}

Nesta seção o termo PC será definido e trabalhos relacionados com o tema, tais como formações de professores para o uso de tecnologias em sala de aula, serão apresentados.

\subsection{Pensamento computacional}

O pensamento computacional aborda conceitos fundamentais da computação que podem ser aplicados na resolução de problemas do dia a dia. Segundo Wing (2006), PC envolve a resolução de problemas, a capacidade de projetar sistemas e a compreensão 
do comportamento humano. O PC possibilita a interdisciplinaridade entre as mais diversas áreas do conhecimento, abordando conceitos como algoritmos, modelagem, automação, coleta de dados, paralelismo, simulação, abstração, análise de dados, representação de dados e decomposição de problemas. A inserção do PC na educação básica não visa tão somente empregabilidade, competitividade e ascensão econômica; mas principalmente a construção de competências e habilidades fundamentais aos seres humanos para o exercício da cidadania no atual século (BLIKSTEIN, 2008). Com isso, existe a real necessidade de levar para a sala de aula práticas que envolvam o uso da computação como ciência integradora.

A computação quando aplicada como ciência possibilita que o aluno construa o seu próprio conhecimento e desenvolva sua capacidade de resolver problemas do cotidiano. O ensino de conceitos básicos de computação nas escolas é fundamental para manter o raciocínio computacional das crianças, pelo seu caráter transversal às demais ciências, possibilitando a formação de cidadãos capazes de viver em um mundo cada vez mais globalizado (NUNES, 2011).

\subsection{Trabalhos relacionados}

Valente (1998) apresenta em seu trabalho uma formação de professores na área de informática na educação objetivando preparar os participantes para o uso do computador em sua sala de aula, alternando adequadamente atividades tradicionais de ensino-aprendizagem e atividades que usam o computador, oportunizando assim condições para os alunos construírem seu conhecimento.

A pesquisa mencionada aborda três pontos fundamentais. Um deles consiste em propiciar ao professor uma nova maneira de representar seu conhecimento. Outro ponto é proporcionar ao professor a vivência de uma experiência que contextualiza o conhecimento que ele constrói. Por último, Valente (1998) destaca que pode-se criar condições para que o professor saiba contextualizar o aprendizado e a experiência vivida durante a sua formação para a sua realidade de sala de aula compatibilizando as necessidades de seus alunos.

No trabalho de Carvalho et al. (2013) o foco está na exploração do PC no ensino médio, em escolas de Minas Gerais, contribuindo para o desenvolvimento da área de TI e, consequentemente, para a formação de uma nova geração de profissionais e cidadãos. $\mathrm{O}$ artigo tem como base o projeto Reinventando o Ensino Médio (REM), organizado pela Secretaria de Educação do Estado de Minas Gerais e implementado com auxílio de professores de Ciência da Computação da Universidade Federal de Minas Gerais. Tal projeto tem três objetivos principais: i) contribuir para a ressignificação da escola pública; ii) gerar competências em áreas de empregabilidade; e iii) preparar os alunos para o prosseguimento dos estudos, temas estes de grande importância para a inserção da computação como ciência em escolas.

O trabalho de Araújo et al. (2016) traz uma experiência na formação de professores do ensino básico das redes Estadual e Municipal de ensino do Rio Grande do Norte (RN) que teve como objetivo apresentar aos participantes a utilização de processos de desenvolvimento de jogos digitais a partir de técnicas de Game Design. O curso contou com a participação de 229 professores e durante as oficinas foram apresentadas as etapas para criação de jogos digitais, prática esta realizada com os professores participantes do projeto. Ao final foi elaborada uma pesquisa para captar o 
feedback dos participantes sobre o aprendizado e o uso futuro do Game Design em salas de aulas com os alunos da rede de ensino público do Rio Grande do Norte. Como resultado, constatou-se que a grande maioria dos participantes demonstrou-se satisfeita quanto ao conhecimento adquirido durante a oficina e boa parte pretende aplicar o aprendizado.

Os trabalhos de Valente (1998) e Araújo et al. (2016) foram escolhidos por terem um foco voltado à formação de professores para o uso de tecnologias na educação e sobre o PC na educação básica, temas de grande importância e que estão inseridos no contexto do projeto desenvolvido no CETEC. O trabalho de Carvalho et al. (2013), por sua vez, tem o foco na exploração do PC no ensino médio, uma questão fundamental para inserção da computação como ciência em escolas, tema também aderente ao projeto desenvolvido e relatado neste trabalho.

\section{Recursos pedagógicos para o ensino de PC}

$\mathrm{Na}$ literatura é possível encontrar diversos recursos que têm sido empregados nas práticas de ensino de PC, dentre os quais pode-se destacar a computação desplugada, jogos e ambientes de programação visual. Exemplos de tais recursos são detalhados nas subseções seguintes, e foram utilizados para a composição de aulas práticas realizadas durante o curso de formação de professores, descrito nas seções 4 e 5 deste artigo.

\subsection{Computação desplugada}

A computação desplugada (http://csunplugged.org/) é um conjunto de atividades práticas que ensina conceitos fundamentais da computação sem o uso do computador, tornando o aprendizado baseado em jogos ou brincadeiras (VIEIRA et al., 2013).

Há uma variedade de atividades que podem ser realizadas em sala de aula, sendo um recurso capaz de promover o ensino de $\mathrm{PC}$, mesmo em escolas que não possuem uma infraestrutura adequada para o ensino de computação. Umas das atividades desplugadas propostas possibilita, por exemplo, o trabalho com o conceito de armazenamento de imagens ou fotografias utilizando apenas combinações de bit 0 e o bit 1. Tal atividade é intitulada de "Colorindo com Números" e ilustrada na Figura 1.

Essa atividade explora o desenvolvimento de habilidades como a contagem e o desenho e tem como matéria correlacionada a Matemática, explorando formas e espaços, e é sugerida para crianças a partir dos sete anos.

Outra atividade que pode ser explorada em salas de aula é intitulada de "Seguindo Instruções", que consiste em seguir instruções pré-determinadas com o objetivo de se chegar a alguma forma, como a ilustrada na Figura 2, criada a partir da seguinte sequência de passos:

- Desenhe um circulo - arco $360^{\circ}$ raio 10 ;

- Vá ao estremo do círculo;

- Desenhe um quadrado - ângulo $90^{\circ}$;

- Vá ao extremo do quadrado;

- Desenhe um triângulo equilátero - ângulo $60^{\circ}$.

Essa atividade tem Português como matéria correlacionada, trabalhando a comunicação, desenvolve habilidades de seguir instruções e é recomendada para crianças a partir dos sete anos. 


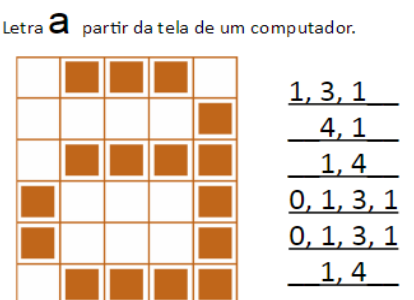

Figura 1. Atividade "Colorindo com Números”
(A)

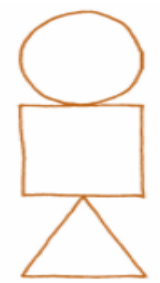

Figura 2. Atividade "Seguindo Instruções"

\subsection{Light Bot}

O Light Bot (https://lightbot.com) é um jogo desenvolvido pela Niato, que tem como principal abordagem o ensino da lógica computacional e noções básicas de algoritmos. Nesta ferramenta é possível executar instruções em um robô para que ele caminhe na plataforma e atinja o objetivo de cada etapa do jogo. A Figura 3 apresenta um dos desafios propostos pela ferramenta.

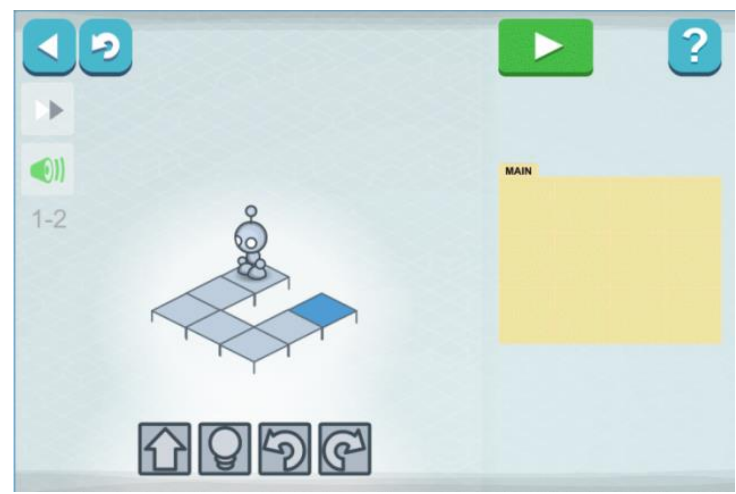

Figura 3. Exemplo de desafio do LightBot.

O desafio do jogo, como pode ser visto na Figura 3, consiste em fazer com que o robô caminhe pelos quadrantes e sempre que ele passar por um quadrado de cor em destaque, acenda a lâmpada. O robô deve fazer isso para todos os quadrados de cor em destaque do cenário para que o desafio seja concluído e o próximo nível seja liberado.

\subsection{Scratch}

Desenvolvido pelo Lifelong Kindergarten Group (LLK), grupo de pesquisa do MIT Media Lab, o ambiente Scratch(https://scratch.mit.edu/) foi criado com o propósito de introduzir a programação de maneira fácil e rápida para aqueles que não possuem nenhum tipo de experiência no assunto (MALONEY et al., 2010).

A ferramenta foi desenvolvida com base na linguagem Logo e Squeak, que trabalha a estrutura de programação em blocos, onde estes por sua vez, podem ser inseridos uns aos outros de forma única e seguindo a lógica de estruturas convencionais da programação.

Como pode ser observado na Figura 4, o ambiente do Scratch é formado pelo palco e diversos elementos ou objetos que podem ser inseridos pelo usuário. Cada objeto pode ter sua estrutura de código desenvolvida, podendo também serem inseridos animações e sons. O ambiente é dividido em módulos, onde cada um deles é 
responsável por uma determinada função. O módulo de controle, por exemplo, é responsável por fornecer blocos de estruturas condicionais e de repetição ao usuário. No bloco de variáveis o programador pode criar ou definir novas variáveis no sistema, inserindo no contexto do jogo ou animação criado por ele. O usuário pode também inserir elementos animação, texto, música ou som para produção de jogos educativos ou com outras finalidades, por exemplo.

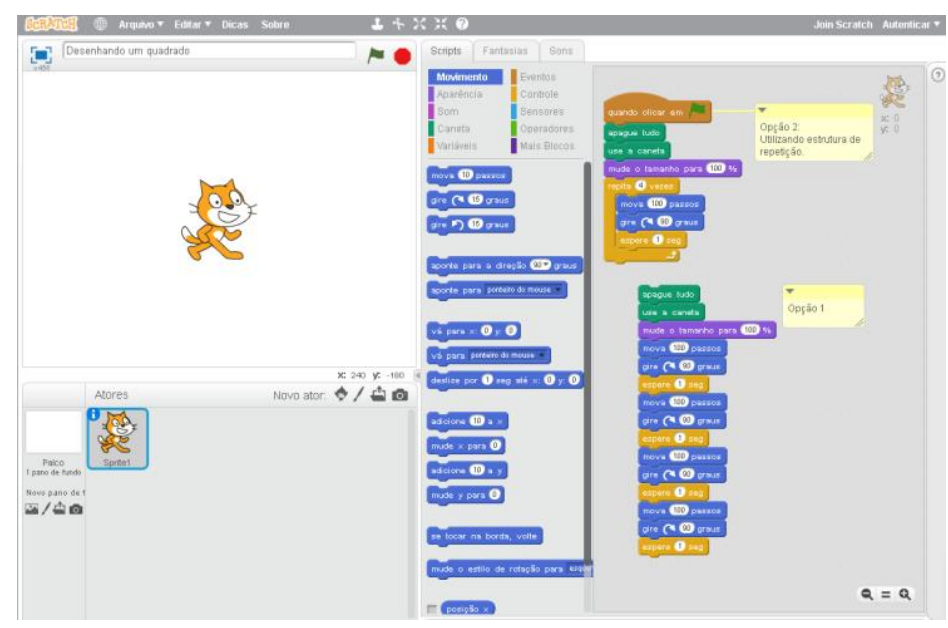

Figura 4. Ambiente de programação Scratch

\section{Proposta de curso e atividades realizadas}

Buscando difundir a computação como uma ciência interdisciplinar, a disciplina Estágio Curricular V do curso de Licenciatura em Computação da UFRPE oportunizou a vivência de um projeto de formação de professores de escolas públicas em PC. Em parceria com o Centro de Tecnologia na Educação (CETEC) da cidade do Recife foi possível planejar a primeira formação de PC, nesta unidade de formação, com previsão de participação de professores com formação pedagógica e tecnológica.

A proposta foi formulada com base no calendário de formações disponibilizado pelo CETEC. O curso, com $16 \mathrm{~h}$ de duração, ocorreu no espaço físico do centro, tendo os professores acesso a notebooks com as ferramentas necessárias para o desenvolvimento do curso já instaladas, como o Scratch. As subseções a seguir apresentam o planejamento do curso e as atividades realizadas durante as aulas práticas com o uso da computação desplugada, do LightBot e do Scratch.

\subsection{Planejamento do curso}

O curso ministrado foi dividido em quatro aulas, com 4 h de duração, cada. O quadro 1 apresenta o cronograma das aulas e os recursos didático-pedagógicos usados para alcançar os objetivos delineados. 
VI Congresso Brasileiro de Informática na Educação (CBIE 2017)

Anais do XXIII Workshop de Informática na Escola (WIE 2017)

Quadro 1. Organização das aulas e seus respectivos objetivos

\begin{tabular}{|c|l|c|}
\hline AULAS & \multicolumn{1}{|c|}{ OBJETIVOS } & $\begin{array}{c}\text { RECURSOS } \\
\text { USADOS }\end{array}$ \\
\hline $\begin{array}{c}\text { 01- Conhecendo o } \\
\text { pensamento } \\
\text { computacional. }\end{array}$ & $\begin{array}{l}\text { Compreender o que é PC, sua importância, e como ele pode ser } \\
\text { aplicado na resolução de problemas do dia a dia. }\end{array}$ & $\begin{array}{c}\text { Atividades } \\
\text { desplugadas }\end{array}$ \\
\hline $\begin{array}{c}02 \text { - Introdução à } \\
\text { lógica de } \\
\text { programação. }\end{array}$ & $\begin{array}{l}\text { Compreender conceitos básicos de lógica de programação, como } \\
\text { variáveis, operadores e função. }\end{array}$ & LightBot \\
\hline $\begin{array}{c}\text { 03 - Conceitos } \\
\text { básicos de } \\
\text { programação. }\end{array}$ & $\begin{array}{l}\text { Compreender e aplicar estruturas de decisão e de repetição na } \\
\text { resolução de problemas. }\end{array}$ & Scratch \\
\hline $04-$ Projeto. & $\begin{array}{l}\text { Explorar e criar projetos no Scratch considerando a área de } \\
\text { formação e atuação do professor participante. }\end{array}$ & Scratch \\
\hline
\end{tabular}

\subsection{Atividades realizadas}

No decorrer do curso, os participantes realizaram atividades desplugadas e com o uso das ferramentas LightBot e Scratch, conforme planejamento, sob a mediação de licenciados em Computação, que auxiliaram na explicação de cada desafio ou atividade proposta.

Uma das atividades propostas foi "A mágica de virar as cartas", ilustrada na Figura 5, e retirada do livro "Computer Science Unplugged". Durante sua realização, foi explanado que quando os dados sejam eles fotos, arquivos de texto ou outros, são armazenados em um disco, pendrive ou até mesmos transmitidos de um computador para outro via rede, pode-se supor que estes foram transmitidos sem falha alguma. Mas eventualmente esses dados podem ser corrompidos por alguma ação inesperada. A atividade realizada demonstra, então, como esses dados corrompidos podem ser detectados pelo computador e como podem ser corrigidos. Este exercício pode permitir o desenvolvimento de habilidades como contagem e reconhecimento de números pares e ímpares, e trabalha matérias como a matemática (Cálculo e estimativa) e álgebra (Padrões e relacionamentos).

Outra atividade realizada contou com o uso do ambiente Scratch, para a prática do uso conceitos de lógica de programação, tais como estruturas condicionais e de repetição. Essa prática teve como intuito desenvolver habilidades de programação. A esse exercício foi dado o nome de "Faça você mesmo", onde os professores participantes deveriam pôr em prática os conceitos discutidos nas aulas e utilizando o ambiente Scratch resolver o desafio proposto:

- Pergunte 'Qual é o seu nome?'

- Crie uma variável chamada 'nome' e outra chamada 'valor1'

- Mude variável 'nome' para resposta

- Pergunte 'Qual nota você tirou em Matemática?'

- Mude 'valor1' da variável para resposta

- Se 'valor1' for maior que 6, junte variável 'nome' com 'você foi aprovado' por 2 segundos

- Senão, junte 'nome' com 'você foi reprovado' por 2 segundos.

\footnotetext{
${ }^{1}$ Disponível em $<$ http://csunplugged.org/wp-content/uploads/2014/12/CSUnpluggedTeachersportuguese-brazil-feb-2011.pdf>
} 
VI Congresso Brasileiro de Informática na Educação (CBIE 2017)

Anais do XXIII Workshop de Informática na Escola (WIE 2017)

Com base no script apresentado, os participantes deveriam construir o código no Scratch, podendo chegar a uma solução como a exposta na Figura 6. Com esses e outros desafios, era esperado que os participantes do curso colocassem em prática os diversos conceitos de PC explorados nas aulas, modificando e criando jogos e animações associados à sua área de formação e atuação, os quais poderão ser explorados em suas salas de aula.

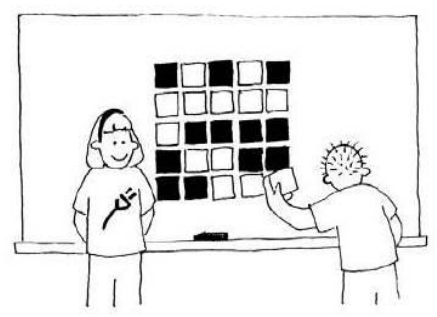

Figura 5. Cenário da atividade "Carta Mágica"

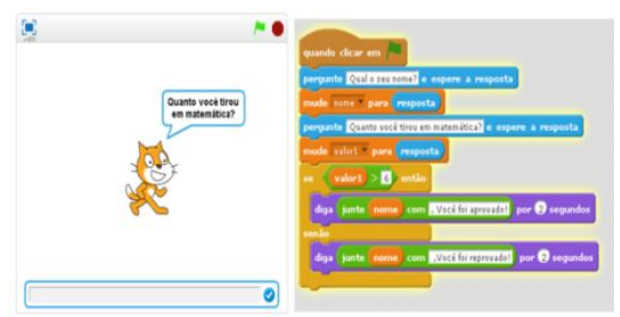

Figura 6. Exemplo de código criado no Scratch

\section{Avaliação do curso}

Em toda formação, os docentes foram receptivos com a proposta e atividades realizadas, ocasionando debates reflexivos acerca do PC e sua aplicação em sala de aula. Ao fim do curso, um questionário foi entregue a cada um dos participantes no intuito de captar suas avaliações sobre o curso ofertado e a adequação das ferramentas apresentadas para uso em suas salas de aula. As perguntas que compunham tal questionário são apresentadas no Quadro 2.

Quadro 2. Itens do questionário

\begin{tabular}{|c|c|c|}
\hline ID & QUESTÃO & $\begin{array}{l}\text { FORMATO DA } \\
\text { RESPOSTA }\end{array}$ \\
\hline 01 & Qual sua área de formação? & Aberta \\
\hline 02 & Qual sua área de atuação? & Aberta \\
\hline 03 & Os professores foram claros e objetivos na explicação dos temas? & Escala Likert \\
\hline 04 & $\begin{array}{l}\text { Na sua percepção, após a formação, o termo "pensamento computacional" } \\
\text { ficou melhor compreendido? }\end{array}$ & Escala Likert \\
\hline 05 & $\begin{array}{l}\text { Em que medida considera que os conteúdos da formação foram úteis ao } \\
\text { exercício da sua função? }\end{array}$ & Escala Likert \\
\hline 06 & $\begin{array}{l}\text { Em que medida considera aplicáveis os conhecimentos adquiridos ao seu } \\
\text { trabalho diário? }\end{array}$ & Escala Likert \\
\hline 07 & Considera que esta formação foi útil para o seu desenvolvimento pessoal? & Escala Likert \\
\hline 08 & Considera que esta formação pode ser útil na progressão da sua carreira? & Escala Likert \\
\hline 09 & Recomendaria este módulo formativo a outros indivíduos? & Escala Likert \\
\hline 10 & Ficou interessado em frequentar outras formações similares? & Escala Likert \\
\hline 11 & Pretende vir a aplicar os conhecimentos que adquiriu no presente módulo? & Escala Likert \\
\hline 12 & $\begin{array}{l}\text { Dos recursos usados no curso qual considera ser o de maior utilidade para a } \\
\text { sua vida profissional? }\end{array}$ & Escala Likert \\
\hline 13 & $\begin{array}{l}\text { Que constrangimentos/obstáculos acha que podem vir a dificultar levar o } \\
\text { que aprendeu no curso para o seu contexto de trabalho? }\end{array}$ & Aberta \\
\hline 14 & Comentários e sugestões. & Aberta \\
\hline
\end{tabular}

Dos participantes presentes, $80 \%$ responderam o questionário. Ao analisarem-se as respostas pode-se citar que: 
VI Congresso Brasileiro de Informática na Educação (CBIE 2017)

Anais do XXIII Workshop de Informática na Escola (WIE 2017)

- Os professores participantes do curso possuem formação pedagógica e tecnológica, e alguns deles lecionam em Unidades de Tecnologia na Educação e Cidadania (UTECs) que ofertam à comunidade cursos sobre Robótica, Animação, Redes Sociais e Internet, Editores de Textos e Planilhas;

- Quanto à clareza e objetividade dos licenciados em Computação na explicação dos temas, $100 \%$ dos participantes assinalaram os itens sempre e na maioria das vezes avaliando, assim, positivamente a abordagem do curso pelos seus formadores;

- Para $100 \%$ dos respondentes, após a formação, o termo "pensamento computacional" ficou melhor compreendido;

- Em relação aos conteúdos apresentados na formação, 70\% responderam que foram úteis ao exercício da sua função e $30 \%$ consideraram que foram muito úteis. $70 \%$ também consideraram esses conteúdos muito aplicáveis ao trabalho, no dia a dia, e outros $30 \%$ responderam na proporção de úteis;

- 100\% consideraram, nas medidas "muito úteis" e "úteis", que a formação foi útil no desenvolvimento pessoal;

- $70 \%$ dos participantes apontaram o Scratch como o software de maior utilidade para a sua prática pedagógica, em detrimento das atividades desplugadas realizadas no curso;

- Sobre os obstáculos que poderiam vir a dificultar a multiplicação dos saberes aprendido, os participantes mencionaram a falta de laboratórios de informática nas escolas e de formação continuada de PC. Ainda, todos os respondentes reportaram sobre a pretensão de aplicar os conhecimentos construídos em sua prática pedagógica; que recomendariam a formação a outros colegas de profissão; e também que desejam participar de outras formações equivalentes.

\section{Discussão e considerações finais}

Este trabalho objetivou difundir a computação como uma ciência interdisciplinar, por meio de um curso de formação de professores em PC. Ao observar-se o quantitativo de professores convocados para a formação (27) com a média de participantes do curso (13), pode-se notar uma possível desmotivação dos professores por possivelmente desconhecem a temática, previamente divulgada, a tirar, por exemplo, dos demais colegas que compareçam e imaginavam que a formação trataria estritamente do uso de tecnologias em sala de aula. Além desse aspecto, identificou-se que a ausência de boa parte dos educadores se deve pela impossibilidade de participação da formação em períodos noturnos, após jornada de trabalho nas escolas, e pela dificuldade de ajustes nos horários entre o deslocamento das unidades escolares até o centro de formação.

No que diz respeito à compreensão do termo PC, foi notório a ampliação da percepção do tema, construído sobre diálogos e debates construtivos sob olhares interdisciplinares. Um dos professores presentes, à medida que a formação estava sendo realizada, reconheceu um dos softwares utilizados, no entanto, ainda não havia feito a associação do termo computacional com o software, para ensino de outras ciências. Destaca-se, ainda, que boa parte dos participantes leciona em UTECs e demonstrou estar motivada em multiplicar os conhecimentos construídos no curso para outros professores e também a alunos de cursos oferecidos nas unidades de tecnologia. 
Os resultados obtidos neste projeto apontam para diversas possibilidades de trabalhos futuros. Um deles perpassa pela disseminação do PC na formação continuada de professores da educação básica, esclarecendo a importância dessa habilidade computacional não somente para cientistas da computação e demonstrando como ela pode ser aplicada na resolução de problemas de outras áreas. Também, uma importante questão de investigação é sobre como professores participantes de cursos similares pretendem integrar o PC em sua prática pedagógica. De modo complementar, pesquisas futuras podem tratar sobre os recursos usados, as habilidades exploradas e como estas podem ser avaliadas em práticas interdisciplinares de PC.

\section{Agradecimentos}

Os autores agradecem a colaboração de Andreza de Santana, Aryesha de Souza e Viviane Figueiredo no planejamento e execução da formação. Também, ao CETEC pelo apoio e abertura para ofertada do curso de pensamento computacional para professores da rede pública de ensino do município de Recife - PE.

\section{Referências}

Araujo, G.; Silva, T.; Aranha, E. A Construção de Jogos Digitais na Escola: um Relato de Experiência na Formação de Professores. Anais do XXII Workshop de Informática na Escola (WIE 2016). p.161-170.

Barr, V.; Stephenson, C. (2011). Bringing computational thinking to K-12: what is Involved and what is the role of the computer science education community? ACM Inroads, 2(1):48-54

Blikstein, P. (2008). O pensamento computacional e a reinvenção do computador na educação. Disponível em: http://www.blikstein.com Acesso em: Julho/2015.

Carvalho, M.; Chaimowicz, L.; Moro, M. M. (2013) "Pensamento Computacional no Ensino Médio Mineiro". In: Anais do XXI WEI, p. 640-649.

Denning, P. J. (2009). The profession of IT: Beyond computational thinking. Commun. ACM, 52(6):28-30

$\mathrm{Hu}, \mathrm{C}$. (2011). Computational thinking: what it might mean and what we might do about it. In Procs. of ITiCSE, pages 223-227, Darmstadt, Alemanha.

Maloney, J.; Resnick, M.; Rusk, N.; Silverman, B.; Eastmond, E. (2010) The scratch programming language and environment. ACM Transactions on Computing Education, vol. 10, n. 4, article 16, 15 pages

Nunes, D. J. (2011). “Ciência da Computação na Educação Básica”. Jornal da Ciência, 09 de Setembro.

Soares, N.; Joaquim J. (2013) Uma escala para medir a infraestrutura escolar. Est. Aval. Educ., São Paulo, v. 24, n. 54, p. 78-99, jan./abr. 2013.

Valente, J.A. (1998). Telepresença na formação de professores da área de Informática em Educação: implantando o construcionismo contextualizado. Actas do IV Congresso Ibero-Americano de Informática na Educação - RIBIE98, Brasília, CD-Rom, /trabalhos/232.pdt

Vieira, A.; Passos, O. ; Barreto, R. (2013). "Um Relato de Experiência do Uso da Técnica Computação Desplugada”. In: Anais do XXI WEI, p. 670-679

Wing, J. M. (2006). Computational thinking. Commun. ACM, 49(3):33-35.

Wing, J. M. (2008). Computational thinking and thinking about computing. Phil. Trans. R. Soc. A, 366(1881):3717-3725. 